\title{
Do health and social support and personal autonomy have an influence on the health- related quality of life of individuals with intellectual disability?
}

Montserrat Alonso-Sardón', Helena Iglesias-de-Sena', Luz Celia Fernández-Martín² and José Antonio Mirón-Canelo ${ }^{1 *}$

\begin{abstract}
Background: The aim of this study was to assess the relation between perceived social support and personal autonomy of individuals with intellectual disabilities and Health-Related Quality of Life.

Methods: A cross-sectional study with a multicentre sample was carried out including 162 institutionalized individuals with intellectual disability. The measurement tool was a structured questionnaire with sociodemographic variables, and three scales: Functional Independence Measure(FIM) scale, Duke-UNC Functional Social Support Questionnaire, and SF-36 Health Survey, which were completed during an individual/family interview.

Results: The perception of received social support is high on all 11 items of the Duke-UNC questionnaire, with an average of 3.45 for item-1 and 4.85 for item-11, which represents a total perceived support of an average 47.98 points ( \pm SD7.30) (normal support). The Mental-Health component is rated worse than Physical-Health (67.41 vs. 71.74). The average rates for the different dimensions range from 57.34 points for Social-Functioning (the lowest rating) to 79.61 points for Bodily-Pain (highest rating). A multiple linear regression analysis reveals that the dimensions of Physical-Functioning $(p<0.001)$, Role-Physical $(p=0.016)$ and Bodily-Pain $(p=0.022)$, which are elements of the Physical-Health component, are independent predictive variables with the Degree of Autonomy (FIM) as a dependent variable. Social-Support (Duke-UNC) as a dependent variable is determined by the dimensions of Vitality $(p=0.014)$, Role-Emotional $(p=0.001)$ and Mental-Health $(p<0.001)$, which are part of the Mental-Health component and act as independent predictive variables.
\end{abstract}

Conclusions: Individuals with intellectual disability and a higher degree of personal autonomy determined by institutional and family support report better Health and Quality of Life.

Keywords: Personal autonomy, Perceived social support, Health-related quality of life, Individuals with intellectual disability

\footnotetext{
* Correspondence: miroxx@usal.es

${ }^{1}$ Area of Preventive Medicine and Public Health, School of Medicine,

University of Salamanca, Institute of Biomedical Research of Salamanca, Avd

de Alfonso X El Sabio s/n, Facultad de Medicina, Universidad de Salamanca,

37007 Salamanca, Spain

Full list of author information is available at the end of the article
}

(c) The Author(s). 2019 Open Access This article is distributed under the terms of the Creative Commons Attribution 4.0 International License (http://creativecommons.org/licenses/by/4.0/), which permits unrestricted use, distribution, and reproduction in any medium, provided you give appropriate credit to the original author(s) and the source, provide a link to the Creative Commons license, and indicate if changes were made. The Creative Commons Public Domain Dedication waiver (http://creativecommons.org/publicdomain/zero/1.0/) applies to the data made available in this article, unless otherwise stated. 


\section{Background}

People with disabilities are an important population group which in 2008 represented 8.5\% $(3,847,900$ people) of the Spanish population. This quantitative impact makes it necessary to assess the major healthcare and social challenges, as well as the social and healthcare costs which it entails, given the levels of dependence of these people for families and for Society [1, 2].

Social support has been significantly associated to the Health-Disease process, and the perception of social support by individuals and their relatives has been systematically related to a good health. On the contrary, dysfunctional or discontinuous social support, or its absence, increases the vulnerability of patients to health problems and diseases. Also, the influence of social support has been observed on other positive health indicators, such as Well-being [3], perceived Health [4] and Quality of Life [5]. Perceived health improves health-related quality of life (HRQoL), and adding social support can improve Well-being, mainly physical and emotional.

Most healthcare professionals are aware that it is necessary to implement a comprehensive policy if we want socio-health care to meet the needs and demands of the most vulnerable social groups in order to achieve a higher degree of integration which guarantees equality of opportunities and equity for these population groups [6]. In this regard, and if we want this inclusion to be effective, it is necessary to obtain the highest possible individual autonomy through the achievement of the maximum development of their physical, cognitive and emotional abilities and/or competences, thus creating adequate and normalized social dynamics which enable individuals with intellectual disability (IIDs) to carry out their basic daily activities and prevent deficiencies or limitations in their activity which may restrict their participation and have an influence on or lead to additional problems and/or dependence.

In order to work in these three professional areas, the approach needs to be multidisciplinary, as an essential tool in the education of IIDs or individuals with developmental disability. For this reason, caregivers, educators, physicians, physical therapists, occupational therapists, speech therapists, psychologists and other professionals must work as a team to correct or minimize those alterations as best as possible, and to guarantee the maximum individual autonomy and social integration so that any person with any kind of disability may have the possibility to come as close as possible to the standard levels of well-being and health-related quality of life (HRQoL) [7] of the general population.

The objective of this social and applied research has been to assess the association and influence of comprehensive care and social support services received by institutionalized IIDs on the improvement of their individual autonomy, their well-being and their HRQoL. With this, the authors intend to increase and improve the evidence on the importance that supports and social assistance have on the quality of life and well-being of this population group.

\section{Methods}

\section{Study design}

In order to reach the objectives, we performed a multicentric cross-sectional population-based descriptive study which was carried out through a personal interview to people with intellectual disability with the support of their caregivers and in the company of their relatives and/or legal guardians; but with prevalence of the opinion of IIDs. In the interviews, caregivers and social workers collaborated together with the purpose of improving the understanding of the questions and thus improve the reliability and validity of the answers.

\section{Sample/participants}

The population of the study are institutionalized IIDs who live in residential homes and attend occupational and/or leisure centres in three Spanish provinces (Salamanca, Zamora and Cáceres), who receive comprehensive health and occupational care in their residence and/ or home or only during daytime, from 9 a.m. to 5 p.m. Criteria for inclusion in the study included obtaining informed consent by the institutionalized subjects who would participate in the study, either given by the IIDs themselves or by their relatives, as well as receiving an authorization by the director of the centre in which they are institutionalized (see Additional file 1). The sample was randomly selected and it returned 162 people with a very similar distribution in the three centres: 55,51 and 46 people, respectively.

\section{Data collection procedures/tools}

The measuring instrument used was a structured questionnaire, which was completed during an individual/ family interview and which includes, on the one hand, sociodemographic variables which will make it possible to characterize the sample (age, sex, percentage of disability, cause of disability, environment and place of residence); and on the other hand the scales for the assessment of function and quality of life parameters which are being studied: Functional Independence Measure (FIM) scale [8], Duke-UNC Functional Social Support Questionnaire [9, 10], and the SF-36 Health Survey [11-14].

The Functional Independence Measure (FIM) scale is a globally accepted tool to measure the degree of disability and the independence of the patients for their activities of daily living (ADL). The scale measures 18 activities 
which are classified into two dimensions, physical and cognitive, and which are in turn divided into 6 categories which measure self-care, sphincter control, transfer, locomotion, communication and social cognition. Each item is scored from 1 to 7 , ranging from total dependence to independence, and the total score ranges from 18 points (total dependence) to 126 points (complete independence), so that the lower the score, the worse the functional level of the patient $[1,2]$. In this study, we have chosen the FIM scale, because the variables it measures include cognitive aspects, communication and interaction with the environment, which are key elements in the life of IIDs. The FIM scale is currently a standard in the global literature which is widely used for different pathologies and age groups, and which has proven to be a valid, sensitive and reliable instrument for the functional assessment of disability.

The Duke-UNC Functional Social Support Scale is a simple and brief tool which assesses the perceived functional or qualitative social support, adapted to the Spanish population and widely used in the caregiver community $[8,9]$. This scale includes 11 items which are scored on a Likert-like scale ranging from 1-"Much less than I would like" to 5- "As much as I would like"; so that the final score is a quantitative measure of the perceived social support: the lower the score, the less the perceived support. The score range of global functional support moves between 11 and 55 points, and the cut-off score to consider that there is perceived support is $<32$ points. The scale is divided into two subscales: confidential social support, which represents the possibility to communicate with other people (items 1, 4, 6, 7, 8, 10); and affective social support, which assesses the received displays of affection and empathy, as well as the availability of people for those displays of affection (items 2, 3, 5, 9, 11) $[9,10]$. It has a grade $B$ of recommendation according to experts [15].

Quality of life was measured with the SF-36 Health Survey, the most widely used questionnaire globally which assesses health-related quality of life in terms of physical and psychological functioning through eight dimensions: Physical Functioning-PF (physical limitations), Role Physical-RP (interference with work and daily activities), Bodily Pain-BP (intensity of pain and its effect on activities), General Health-GH (personal assessment of health), Vitality-VT (feeling of energy), Social Functioning-SF (interference with normal social activities), Role Emotional-RE (interference with work or other daily activities) and Mental Health-MH (depression, anxiety, control of emotions and behaviour). It is expressed as a score on a $0-100$ scale in which higher scores represent better quality of life. This questionnaire has a grade A of recommendation according to experts [15] and has been used with people with low levels of education and IIDs [16-18]. HRQoL with social supports improves individual functioning and, consequently, improves both physical and emotional Well-being.

The fieldwork was carried out during the last quarter of the year 2015 and the first quarter of the year 2016. The interviews were made in the centers where IIDs are institutionalized and always in the presence of the caregivers and social workers.

The personal interview as a social research technique makes it possible to obtain the desired information from a specific subject beforehand through a direct conversation, based on a structured questionnaire. That is, all the subjects interviewed are asked the same questions, in the same way, and in the same order. Therefore, the questionnaire was applied to the selected IIDs in front of their families or of professionals from supporting institutions in cases in which the subject had a greater dependence. In all cases, questions were adapted to the level of understanding of IIDs by social workers. They have great experience in dealing with IIDs. In this way, we try to control bias and improve the validity of the study.

\section{Ethics}

This study was reviewed and approved by the Clinical Research Ethics Committee for Clinical Investigation of the University Hospital of Salamanca (see Additional file 2).

\section{Statistical analyses}

The data obtained were included in a database which had been specifically created for this research, and they were analysed with the statistical software package SPSS 23.0. The statistical analysis included a descriptive study of frequency distribution of all variables (univariate analysis). Quantitative results are expressed as arithmetic mean and standard deviation (SD), qualitative results are expressed as relative frequencies (percentage or proportion), accompanied by their corresponding $95 \%$ confidence intervals $(95 \% \mathrm{CI})$, which make it possible to assess the population parameter through the values observed in the different variables of the individuals in the sample. On the other hand, a multiple linear regression model was used to explore and quantify the relation between the scores (quantitative variables) obtained in the different scales/questionnaires of functional assessment and quality of life that were applied (multivariate analysis). The results are included in simplified tables which show the regression coefficient (B), 95\% CI for B and statistical significance (p). Finally, the researchers in this study have defined a $p$-value for statistical significance of $p<0.05$.

\section{Results}

The study includes 162 adult patients, 58\% (94) are men and $42 \%$ (68) are women. The average age is 50.8 years \pm 
SD 12.85 (range: $21-80$ years). Most of the subjects live in residential homes and go to occupational and/or leisure centres $(112 ; 69.1 \%)$. The degree of disability of these people ranges from 36 to $100 \%$, and the average is $76.17 \% \pm$ SD 10.38.

Tables 1 and 2 show the qualitative and quantitative results, respectively, which were obtained in the FIM Scale. As can be seen in Table 1, with regard to Self-care, the subjects did not generally require care (levels 6 and 7) for each of the functions analysed, with percentages ranging from $53.1 \%$ (eating) to $32.7 \%$ (bathing/showering). Also, bathing/showering is the activity which more often requires total assistance (levels 1 and 2), with $29 \%$. Most of the subjects can control their sphincters. 66$67 \%$ of the subjects do not require help in this regard (levels 6 and 7), while only 10\% show complete dependence (levels 1 and 2). With regard to mobility and locomotion, most of them do not require help (levels 6 and 7), with percentages ranging from 59.3\% (transfers: bathtub/shower) to $70.4 \%$ (transfers: bed/ chair). Communication and cognition are the functions with the highest levels of complete (levels 1 and 2) and partial dependence (levels 3, 4 and 5), and problem solving scores in some of these levels in the highest proportion (81.5\%). Therefore, only $18.5 \%$ of the patients consider themselves to be able to solve problems.
Table 2 shows the quantitative data obtained in the different categories, sub-scales and dimensions. It may be highlighted that the average score for physical dimension was 66.59 ( \pm SD 23.28) out of a total of 91 points, whereas the score for the cognitive dimension is 20.17 ( \pm SD 10.25), out of a maximum of 35 points.

The results obtained in the Duke-UNC Functional Social Support Scale are presented in Table 3. In general terms, we may highlight that there is a high perception of received social support in the 11 items of the questionnaire (4 "Almost as much as I would like" and 5 "As much as I would like" in the Likert scale), with average scores ranging from 3.45 in item 1 "I receive visits from friends and relatives" to 4.85 in item 11 "I get help when I am sick in bed", which represents an average total perceived support of 47.98 points $( \pm$ SD 7.30) (normal support), which is much higher than the established cut-off value (32 points). In 154 out of the 162 IIDs in our study (95\%), the perceived social support was normal. A specific analysis of the confidential and affective support reveals an average of $25.71( \pm$ SD 4.69$)$ and $22.40( \pm$ SD 2.97) points, respectively, and these scores are higher than the established cut-off values (18 points for confidential support and 15 points for affective support).

Table 4 includes the descriptive statistics for each of the health components and dimensions of the SF-36 Survey. In general terms, the Mental Health component

Table 1 Main qualitative results obtained in the FIM scale

\begin{tabular}{|c|c|c|c|c|c|c|c|}
\hline \multirow[t]{3}{*}{ FIM } & \multirow[t]{3}{*}{ Categories } & \multicolumn{2}{|c|}{ Complete dependence } & \multirow{2}{*}{\multicolumn{2}{|c|}{$\frac{\text { Modified dependence }}{\text { Levels } 3,4,5}$}} & \multirow{2}{*}{\multicolumn{2}{|c|}{$\begin{array}{l}\text { No assistance } \\
\text { Level 6,7 }\end{array}$}} \\
\hline & & \multicolumn{2}{|c|}{ Levels 1,2 } & & & & \\
\hline & & $\mathrm{F}$ & $\% \pm 95 \% \mathrm{Cl}$ & $\mathrm{F}$ & $\% \pm 95 \% \mathrm{Cl}$ & $\mathrm{F}$ & $\% \pm 95 \% \mathrm{Cl}$ \\
\hline \multirow[t]{6}{*}{ Self-care } & Eating & 20 & $12.3 \pm 5$ & 56 & $34.6 \pm 7$ & 86 & $53.1 \pm 8$ \\
\hline & Grooming & 25 & $15.4 \pm 6$ & 55 & $34 \pm 7$ & 82 & $50.6 \pm 8$ \\
\hline & Bathing/showering & 47 & $29 \pm 7$ & 62 & $38.3 \pm 7$ & 53 & $32.7 \pm 7$ \\
\hline & Dressing upper body & 28 & $17.3 \pm 6$ & 56 & $34.6 \pm 7$ & 78 & $48.1 \pm 8$ \\
\hline & Dressing lower body & 29 & $17.9 \pm 6$ & 53 & $32.7 \pm 7$ & 80 & $49.4 \pm 8$ \\
\hline & Toileting & 45 & $27.8 \pm 7$ & 63 & $38.9 \pm 8$ & 54 & $33.3 \pm 7$ \\
\hline \multirow[t]{2}{*}{ Sphincter control } & Bladder & 16 & $9.9 \pm 5$ & 37 & $22.8 \pm 6$ & 109 & $67.3 \pm 7$ \\
\hline & Bowel & 14 & $8.6 \pm 4$ & 40 & $24.7 \pm 7$ & 108 & $66.7 \pm 7$ \\
\hline \multirow[t]{3}{*}{ Mobility } & Bed/chair & 19 & $11.7 \pm 5$ & 29 & $17.9 \pm 6$ & 114 & $70.4 \pm 7$ \\
\hline & Toilet & 18 & $11.1 \pm 5$ & 31 & $19.1 \pm 6$ & 113 & $69.8 \pm 7$ \\
\hline & Bathtub/shower & 25 & $15.4 \pm 6$ & 41 & $25.3 \pm 7$ & 96 & $59.3 \pm 8$ \\
\hline \multirow[t]{2}{*}{ Transfers } & Walking/wheelchair & 19 & $11.7 \pm 5$ & 29 & $17.9 \pm 6$ & 114 & $70.4 \pm 7$ \\
\hline & Stairs & 23 & $14.2 \pm 5$ & 34 & $21 \pm 6$ & 105 & $64.8 \pm 7$ \\
\hline \multirow[t]{2}{*}{ Communication } & Comprehension & 24 & $14.8 \pm 5$ & 84 & $51.9 \pm 8$ & 54 & $33.3 \pm 7$ \\
\hline & Expression & 35 & $21.6 \pm 6$ & 79 & $48.8 \pm 8$ & 48 & $29.6 \pm 7$ \\
\hline \multirow[t]{3}{*}{ Social cognition } & Social interaction & 38 & $23.5 \pm 7$ & 80 & $49.4 \pm 8$ & 44 & $27.2 \pm 7$ \\
\hline & Problem solving & 65 & $40.1 \pm 8$ & 67 & $41.4 \pm 8$ & 30 & $18.5 \pm 6$ \\
\hline & Memory & 50 & $30.9 \pm 7$ & 70 & $43.2 \pm 8$ & 42 & $25.9 \pm 7$ \\
\hline
\end{tabular}


Table 2 Main quantitative results obtained in the FIM scale

\begin{tabular}{|c|c|c|c|c|c|c|c|c|}
\hline \multirow[t]{2}{*}{ FIM } & & \multicolumn{2}{|c|}{ Categories } & $\underline{\text { Subscales }}$ & \multicolumn{2}{|c|}{ Domains } & \multicolumn{2}{|l|}{ Total FIM } \\
\hline & & Mean & $\pm S D$ & Mean & Mean & $\pm S D$ & Mean & $\pm S D$ \\
\hline \multirow[t]{6}{*}{ Self-care } & Eating & 5.25 & \pm 1.85 & \multirow[t]{3}{*}{ Self-care (max. 35 points) } & \multirow{7}{*}{\multicolumn{2}{|c|}{ Motor (max. 91 points) }} & \multirow[t]{8}{*}{ Total (max. } & 126 points) \\
\hline & Grooming & 5.03 & \pm 2.02 & & & & & \\
\hline & Bathing/showering & 4.15 & \pm 2.23 & & & & & \\
\hline & Dressing upper body & 4.94 & \pm 2.06 & \multirow[t]{3}{*}{ \pm 11.51} & & & & \\
\hline & Dressing lower body & 4.94 & \pm 2.11 & & & & & \\
\hline & Toileting & 4.17 & \pm 2.25 & & & & & \\
\hline \multirow[t]{2}{*}{ Sphincter control } & Bladder & 5.63 & \pm 1.85 & Sphincter c. (max. 14 points) & & & & \\
\hline & Bowel & 5.71 & \pm 1.76 & \pm 3.60 & 66.59 & \pm 23.28 & & \\
\hline \multirow[t]{3}{*}{ Mobility } & Bed/chair & 5.67 & \pm 1.92 & Mobility (max. 21 points) & & & & \\
\hline & Toilet & 5.68 & \pm 1.90 & \multirow[t]{2}{*}{ \pm 5.68} & & & \multirow[t]{4}{*}{86.65} & \multirow[t]{4}{*}{ \pm 30.28} \\
\hline & Bathtub/shower & 5.27 & \pm 2.06 & & & & & \\
\hline \multirow[t]{2}{*}{ Transfers } & Walking/wheelchair & 5.69 & \pm 1.87 & Transfers (max. 14 points) & & & & \\
\hline & Stairs & 5.43 & \pm 2.05 & \pm 3.93 & & & & \\
\hline \multirow[t]{2}{*}{ Communication } & Comprehension & 4.33 & \pm 1.77 & Communication (max. 14 points) & \multirow{2}{*}{\multicolumn{2}{|c|}{ Cognitive (max. 35 points) }} & & \\
\hline & Expression & 4.17 & \pm 1.89 & \pm 3.64 & & & & \\
\hline \multirow[t]{3}{*}{ Social cognition } & Social interaction & 4.06 & \pm 1.86 & Social cog. (max. 21 points) & & & & \\
\hline & Problem solving & 3.31 & \pm 1.89 & \multirow[t]{2}{*}{ \pm 5.34} & \multirow[t]{2}{*}{20.17} & \multirow[t]{2}{*}{ \pm 10.25} & & \\
\hline & Memory & 3.75 & \pm 1.94 & & & & & \\
\hline
\end{tabular}

Table 3 Main results obtained in the DUKE-UNC Functional Social Support

\begin{tabular}{|c|c|c|c|c|c|c|c|}
\hline \multicolumn{2}{|r|}{ DUKE-UNC Functional Social Support } & \multicolumn{5}{|c|}{ Descriptive study of frequencies } & \multirow{3}{*}{$\begin{array}{l}\text { Descriptive } \\
\text { statistics }\end{array}$} \\
\hline & & \multirow{3}{*}{$\begin{array}{l}1 \\
\text { Much less than } \\
\text { I would like }\end{array}$} & \multirow{3}{*}{$\begin{array}{l}2 \\
\text { Less than I } \\
\text { would like } \\
\text { Freq. (\%) }\end{array}$} & \multirow{2}{*}{$\begin{array}{l}3 \\
\text { Some, but } \\
\text { would like } \\
\text { more }\end{array}$} & \multirow{2}{*}{$\begin{array}{l} \\
\text { Almost as much } \\
\text { as I would like }\end{array}$} & \multirow{2}{*}{$\begin{array}{l}5 \\
\text { As much as I } \\
\text { would like }\end{array}$} & \\
\hline & & & & & & & \\
\hline & & & & Freq. (\%) & Freq. (\%) & Freq. (\%) & $\overline{\operatorname{Mean}( \pm \mathrm{SD})}$ \\
\hline 1 & I receive visits from my friends and relatives & $30(18.5 \%)$ & $22(13.6 \%)$ & $19(11.7 \%)$ & $27(16.7 \%)$ & $64(39.5 \%)$ & $3.45( \pm 1.56)$ \\
\hline 2 & I receive help around the house & $4(2.5 \%)$ & $9(5.6 \%)$ & $23(14.2 \%)$ & $42(25.9 \%)$ & $84(51.9 \%)$ & $4.19( \pm 1.03)$ \\
\hline 3 & I receive praise for a good job & & $4(2.5 \%)$ & $6(3.7 \%)$ & $45(27.8 \%)$ & $107(66.0 \%)$ & $4.57( \pm 0.68)$ \\
\hline 4 & I have people who care what happens to me & & $3(1.9 \%)$ & $8(4.9 \%)$ & $30(18.5 \%)$ & $121(74.7 \%)$ & $4.66( \pm 0.66)$ \\
\hline 5 & I get love and affection & & $9(5.6 \%)$ & $4(2.5 \%)$ & $40(24.7 \%)$ & $109(67.3 \%)$ & $4.53( \pm 0.79)$ \\
\hline 6 & $\begin{array}{l}\text { I get chances to talk to someone about } \\
\text { problems at work or with my housework }\end{array}$ & $3(1.9 \%)$ & $9(5.6 \%)$ & $8(4.9 \%)$ & $40(24.7 \%)$ & $102(63.0 \%)$ & $4.41( \pm 0.94)$ \\
\hline 7 & $\begin{array}{l}\text { I get chances to talk to someone about my } \\
\text { personal or family problems }\end{array}$ & $1(0.6 \%)$ & $9(5.6 \%)$ & $15(9.3 \%)$ & $36(22.2 \%)$ & $101(62.3 \%)$ & $4.40( \pm 0.91)$ \\
\hline 8 & $\begin{array}{l}\text { I get chances to talk to someone about } \\
\text { money matters }\end{array}$ & & $11(6.8 \%)$ & $18(11.1 \%)$ & $36(22.2 \%)$ & $97(59.9 \%)$ & $4.35( \pm 0.92)$ \\
\hline 9 & $\begin{array}{l}\text { I get invitations to go out and do things with } \\
\text { other people }\end{array}$ & & $13(8.0 \%)$ & $17(10.5 \%)$ & 49 (30.2\%) & $83(51.2 \%)$ & $4.24( \pm 0.93)$ \\
\hline 10 & $\begin{array}{l}\text { I get useful advice about important things in } \\
\text { life }\end{array}$ & & $5(3.1 \%)$ & $17(10.5 \%)$ & $42(25.9 \%)$ & $98(60.5 \%)$ & $4.43( \pm 0.80)$ \\
\hline 11 & I get help when I am sick in bed & & $2(1.2 \%)$ & $1(0.6 \%)$ & $15(9.3 \%)$ & $144(88.9 \%)$ & $4.85( \pm 0.45)$ \\
\hline \multicolumn{2}{|c|}{ Total Perceived Support } & \multicolumn{5}{|c|}{$\leq 32$ points-Low support; $\geq 33$ points-Normal support } & $\begin{array}{l}47.98 \\
( \pm 7.30)\end{array}$ \\
\hline
\end{tabular}


Table 4 Main results obtained in the SF-36

\begin{tabular}{lll}
\hline SF-36 Dimensions & \multicolumn{2}{l}{ Descriptive statistics } \\
\cline { 2 - 3 } & Mean & \pm Standard Dev. \\
\hline Physical Functioning (PF) & 71.55 & 33.79 \\
Role-Physical (RP) & 75.30 & 41.13 \\
Bodily Pain (BP) & 79.61 & 27.08 \\
General Health (GH) & 59.32 & 21.03 \\
Physical health COMPONENT (PHC) & 71.74 & 25.68 \\
Vitality (VT) & 69.25 & 20.30 \\
Social Functioning (SF) & 57.34 & 21.61 \\
Role-Emotional (RE) & 69.13 & 40.96 \\
Mental Health (MH) & 73.92 & 19.85 \\
Mental health COMPONENT (MHC) & 67.41 & 18.91 \\
$\quad$ Health Transition Item & 48.46 & 17.55 \\
\hline
\end{tabular}

received worse scores than the Physical Health component (67.41 vs. 71.74). The average scores of the dimensions range from 57.34 points for Social Functioning (lowest rating) to 79.61 points for Bodily Pain (highest rating).

Figure 1 compares the values obtained in the institutionalized population with intellectual disability with the reference values of the general population and the values of their non-institutionalized peers. The largest differences are observed in the Social Functioning component, both between the two groups of IIDs (institutionalized and non-institutionalized) and with regard to the general population of reference.
The association study between the sociodemographic variables included and the different scales/surveys of functional assessment and HRQoL used in the study reveals some results which are worth highlighting. The independent variable sex is not significantly associated $(p>0.05)$ to any of the scales, sub-scales, domains or components of the different surveys and/or scales, whereas the variable age is significantly associated to the perceived social support in the Duke-UNC questionnaire $(p=0.027)$ and to some dimensions of the SF-36 Survey: Physical Functioning $(p=0.029)$, Vitality $(p=0.009)$ and Mental Health $(p=0.045)$. With regard to the independent variable rural/urban origin, it is significantly associated to perceived social support in the Duke-UNC Questionnaire $(p<0.001)$, the cognitive domain of the FIM Scale $(p=0.015)$ and some dimensions of the SF-36 Survey: Physical Functioning $(p=0.012)$, General Health $(p=0.016)$, Vitality $(p=0.001)$ and Mental Health $(\mathrm{p}=$ 0.001 ). With regard to the degree of disability, it was significantly associated to all the sub-scales and domains of the FIM Scale $(p<0.05)$, but not with the perceived social support of the Duke-UNC Questionnaire or any of the dimensions of the SF-36 Survey ( $p>0.05)$.

The multiple linear regression analysis with the FIM Scale as a dependent variable reveals that the dimensions of Physical Functioning $(p<0.001)$, Role Physical $(\mathrm{p}=0.016)$ and Bodily Pain $(p=0.022)$, which are elements of the Physical Health component, are independent predictive variables. On the other hand, an analysis with the Duke-UNC Questionnaire as a dependent

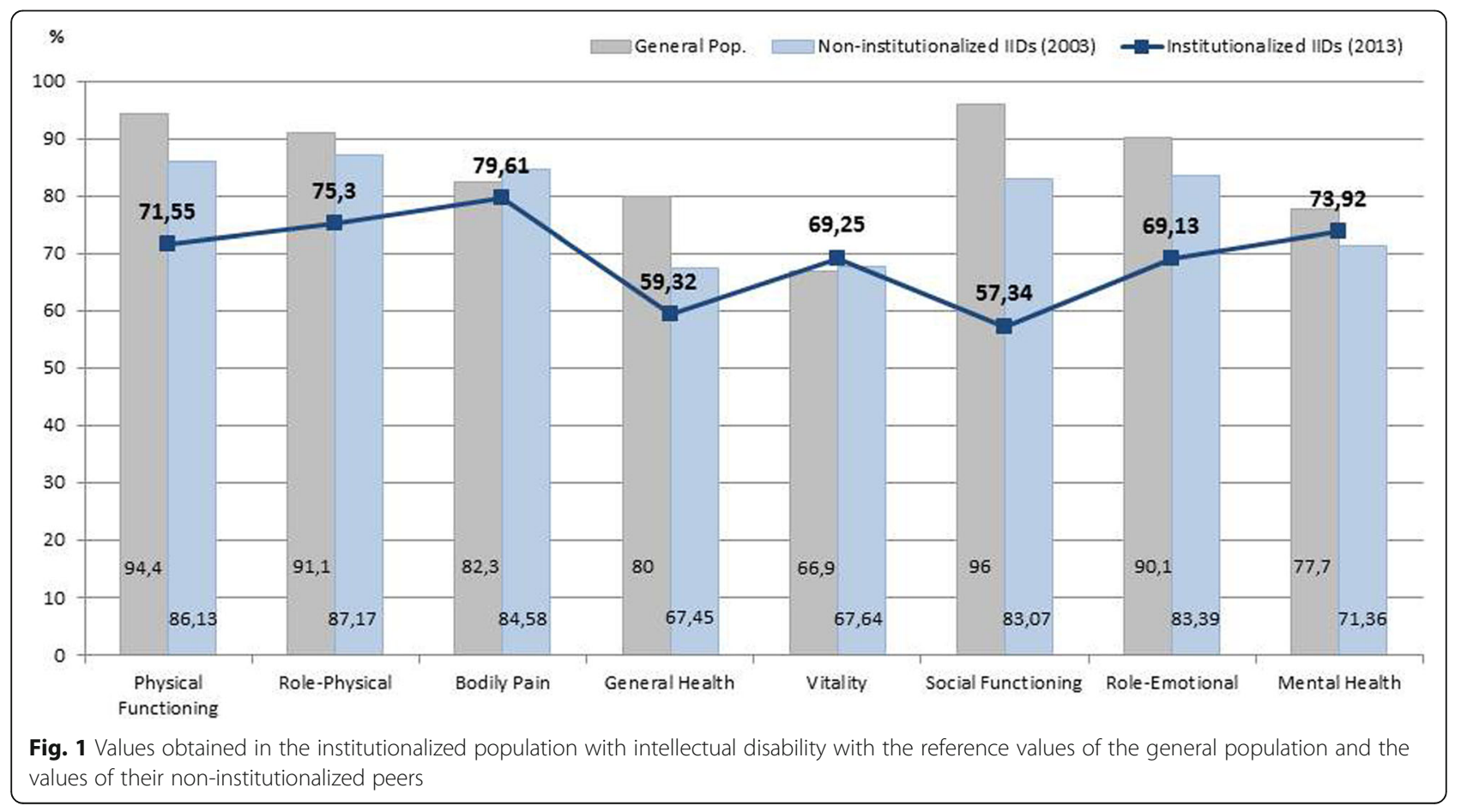


variable shows that the dimensions of Vitality ( $p=$ $0.014)$, Role-Emotional $(p=0.001)$ and Mental Health ( $\mathrm{p}$ $<0.001$ ), which belong to the Mental Health component, act as independent predictive variables (see Table 5).

\section{Discussion}

Our findings show that the IIDs in our study report an adequate level of Perceived Social Support (PSS), and that families are the main providers of that support. These results are explained by the role traditionally played by families in Spain. These observations are in keeping with those of other authors which claim that family support is associated to a better perception of quality of life, although we are aware that this role may be overvalued compared with other types of social support [19].

Most of the participants in the study have a good family support, which represents a mechanism of protection and tutelage against stressful situations, since the data reveal that a normal functioning family network fulfils a social function and a social responsibility. Recent studies carried out in Spain highlight the relevant role of families, which have beneficial effects during adult and old age because they make it possible to manage stressful situations and they act as a protective element [20]. This role is beginning to be assessed with new tools, and it is therefore still necessary to establish the validity and reliability of these results [21].

In this study, the sample of the analysis is made up of IIDs who live in institutional residential centres and attend occupational and/or leisure centres with similar human and professional resources for their care, since they all belong to the same federation of associations of IIDs (FEAPS). Therefore, they all have the same aim and organic and functional structure. Consequently, users receive virtually constant support and supervision by their caregivers and educators, in spite of the fact that in some cases it may not be really necessary. We are aware that this factor may have an influence on the results, since it reduces the real level of independence of each subject; however, it is necessary to assess the adaptation and effectiveness of these centres with regard to their main aim, which is to improve the Quality of Life of IIDs. This is an aspect which is beginning to be assessed in other countries as well [22]. With regard to non-institutionalized IIDs, significant differences are observed with regard to the factors of Physical Functioning, General Health, Social Functioning and Role-Emotional, probably due to a worse situation and to the fact that they spend more time in the centres and less time is dedicated to other interpersonal and social relationships [17]. This result is coherent, since the components of Physical Functioning and Role-Physical are determinant factors for General Health and Vitality. On the other hand, Social Functioning is conditioned by these elements, but mainly by the attitude of the parents and guardians. With regard to the Mental Health component, which shows a similar level in both populations, this finding may be due to a lack of understanding and objective judgement on the implications of this component [17].

With regard to the relation between social functioning and emotional state, the sample is characterized by the possibility of communicating with and showing affection or empathy to other people, which makes it possible to attain a dynamic balance in their emotional state. Consequently, social support is related to their emotional well-being, and it has been proven that the more perceived social support there is, the less emotional problems will the older IID develop. The results confirm the important role played by social support and services on emotional state and perceived health during adult age.

Table 5 Multiple linear regression analysis between FIM scale and Duke-UNC (dependent variables) and the Dimensions of SF-36 (predictive variables)

\begin{tabular}{|c|c|c|c|c|c|c|c|c|c|}
\hline \multirow{4}{*}{$\frac{\text { Predictive variables }}{\text { Dimensions SF-36 }}$} & & \multicolumn{8}{|c|}{ Dependent variable } \\
\hline & & \multicolumn{4}{|c|}{ Total FIM } & \multicolumn{4}{|c|}{ Duke-UNC Total perceived support } \\
\hline & & \multirow[t]{2}{*}{ B } & \multicolumn{2}{|c|}{$95 \% \mathrm{Cl}$ for $\mathrm{B}$} & \multirow[t]{2}{*}{ Sig. } & \multirow[t]{2}{*}{ B } & \multicolumn{2}{|c|}{$95 \% \mathrm{Cl}$ for $\mathrm{B}$} & \multirow[t]{2}{*}{ Sig. } \\
\hline & & & Lower I. & Upper I. & & & Lower I. & Upper I. & \\
\hline \multirow[t]{4}{*}{ Physical Health Component (PHC) } & Physical Functioning & 0.543 & 0.386 & 0.701 & $0.000^{*}$ & 0.013 & -0.028 & 0.054 & 0.528 \\
\hline & Role-Physical & 0.180 & 0.033 & 0.327 & $0.016^{*}$ & -0.011 & -0.049 & 0.027 & 0.562 \\
\hline & Bodily Pain & -0.287 & -0.532 & -0.042 & $0.022^{*}$ & -0.096 & -0.159 & -0.033 & $0.003^{*}$ \\
\hline & General Health & 0.063 & -0.227 & 0.353 & 0.666 & 0.032 & -0.043 & 0.107 & 0.406 \\
\hline \multirow[t]{4}{*}{ Mental Health Component (MHC) } & Vitality & -0.261 & -0.630 & 0.108 & 0.164 & 0.120 & 0.025 & 0.216 & $0.014^{*}$ \\
\hline & Social Functioning & 0.087 & -0.096 & 0.271 & 0.348 & -0.018 & -0.065 & 0.029 & 0.455 \\
\hline & Role-Emotional & 0.118 & -0.004 & 0.239 & 0.059 & -0.054 & -0.085 & -0.022 & $0.001^{*}$ \\
\hline & Mental Health & 0.040 & -0.289 & 0.369 & 0.810 & 0.162 & 0.077 & 0.247 & $0.000^{*}$ \\
\hline
\end{tabular}


The subjects who live within a community context enjoy a better psychosocial adjustment, which is reflected in a higher participatory and perceived social support, whereas residents without social support report a poorer state of physical and emotional health, with low levels of self-esteem, and with friends as the main source of support. This aspect has been highlighted by a recently published systematic review in relation with the general population [23].

This finding confirms the existing relation between life conditions and personal satisfaction which is influenced by personal values and determines the quality of life of people. Therefore, it may be claimed that better life conditions lead to a better quality of life; and that the higher the personal satisfaction, the higher the Quality of Life, and that the more culture and maturity (personal values), the higher the Quality of Life [11, 14].

All these findings have been proven in a sample of institutionalized and non-institutionalized subjects over 65 years old, in which it was observed that the relational aspect was the most relevant one in non-institutionalized elderly people, and that they derived a high perception of satisfaction through family support, whereas for institutionalized subjects, the main source of support were social relational aspects [24]. The positive effect provided by PSS is clear in the general population: these benefits represent higher well-being for elderly people and their families, decrease the feelings of isolation and promote healthy behaviour. More specifically, in the field of Health, social support is important to face stress and disease, but we must be aware that in IIDs, supportive interpersonal and social relations may be both positive and negative, as some studies have reported [25]. Social support has been presented as a useful element in the maintenance of Health and to prevent the adjustment disorders and psychopathologies which are characteristic of IIDs [26]. It may also play an important role in the reduced prevalence of some classic risk factors, such as tobacco and alcohol. This last factor has not been widely researched in IIDs because families tend to be overprotective and reduce the consumption of these substances [27]; but some essays are starting to assess support interventions to reduce their consumption [28]. On the other hand, some recent studies claim that social support does not replace formal healthcare with regard to Health, but that it is a complement for it [29].

Finally, with regard to the PSS measured by the Duke-UNC questionnaire, we have observed a favourable assessment of their social relations (relatives and close friends), probably related to the possibility of maintaining an empathic and emotive communication with them, both at an affective and at a confidential level. It may be claimed that the level of affective and confidential support and the total perceived support level of the sample are relevant because they largely exceed the established value of reference from a healthcare perspective. In our country, there are only studies of interventions with caregivers of dependent people, elderly people and immobilized patients at their homes [30-32].

It may be added that based on what we have observed through the SF-36 Survey in this sample of IIDs, this deficit in cognitive knowledge protects the patients against the current chronic and/or neurodegenerative diseases which are associated to the process of ageing and which represent the biggest concern in the general population. The cognitive deficit of IIDs with regard to the concepts of Health-Disease acts as a simple protection in which they are not aware of the transcendence of certain ailments [33, 34]. This mechanism probably works similarly to the way in which their relatives protect them from classic risk factors like tobacco and alcohol consumption and to the way in which their family and social support assist them in their daily life to meet the social integration challenges and needs that may arise $[16,27]$.

\section{Limitations and strengths}

The most important limitation in this study is related to the difficulty of IIDs to understand the items of the sub-scales or the components of the SF-36 Survey of Health-Related Quality of Life. As an example, the Mental Health component, which is already difficult to understand for a normal person, is much more elusive for IIDs who lack the objective judgement to understand its meaning and to assess their own mental health. This limitation may account for the fact that their levels are similar to those of the general population of reference. We have attempted to control this limitation through the support of their caregivers, who know them perfectly and who report that the subjects are IIDs but know what is happening to them and what is good for them, that they are not stupid and are capable of understanding and assimilating information, and of acting accordingly [35].

The authors are aware of these limitations and we consider that the main strength of this multicentric study is to simultaneously use three measurement instruments that are usually used independently in most of the studies reviewed. In this way, we want to show a more objective view of HRQoL in IIDs.

\section{Conclusions}

In conclusion, we may declare that Individuals with Intellectual Disability with a higher degree of Personal Autonomy associated to received and perceived family and institutional support report a significantly higher General Health, Well-being and HRQoL than subjects who are more dependent and have less support. 
Finally, it will be necessary to carry out future intervention studies that combine qualitative and quantitative methodologies to assess HRQoL, PSS and Autonomy in people with different degrees and types of disability in order to enact the Rights established in the UN Convention on the Rights of Persons with Disabilities and, consequently, to provide a better Social Function and Integration.

\section{Additional files}

Additional file 1: Statement of parental/legal guardian consent to participate (PDF $170 \mathrm{~kb}$ )

Additional file 2: Ethics Committee. (PDF $176 \mathrm{~kb}$ )

\section{Abbreviations}

95\% Cl: 95\% confidence intervals; ADL: Activities of daily living; BP: Bodily Pain; FIM scale: Functional Independence Measure scale; GH: General Health; HRQOL: Health-related quality of life; IIDs: Individuals with intellectual disability; MH: Mental Health; PF: Physical Functioning; PSS: Perceived social support; RE: Role Emotional; RP: Role Physical; SD: Standard deviation; SF: Social Functioning; SF-36: Short Form-36 Health Survey; VT: Vitality

\section{Acknowledgements}

The authors acknowledge people with intellectual disability and their families their availability, participation and collaboration in this study.

\section{Funding}

No funding was received.

\section{Availability of data and materials}

Dataset generated and/or analyzed during the current study are available from the mains authors upon reasonable request from another investigator or institution dedicated to investigation to email addresses: sardonm@usal.es or miroxx@usal.es.

\section{Authors' contributions}

MAS, HIdeS and JAMC conceptualized the study and design, analysed and interpreted the data, in addition to drafting the manuscript. LCFM revised the article and advised the caregivers and social workers in social and communication skills with the purpose of a better understanding and motivation for the interview. All authors have read and approved the final version of the manuscript.

\section{Ethics approval and consent to participate}

This study was reviewed and approved by the Clinical Research Ethics Committee for Clinical Investigation of the University Hospital of Salamanca (Additional file 2).

Because it's a multicentric study, informed consent was requested from parents, family and guardianship foundations by the Centers where IIDs reside. Informed consent was verbal and obtained from all individual participants included in the study. This procedure was approved by the Ethics Committee.

\section{Consent for publication}

This manuscript contains no individual personas data. "Not applicable" in this section.

\section{Competing interests}

The authors declare that they have no competing interests.

\section{Publisher's Note}

Springer Nature remains neutral with regard to jurisdictional claims in published maps and institutional affiliations.

\section{Author details}

Area of Preventive Medicine and Public Health, School of Medicine, University of Salamanca, Institute of Biomedical Research of Salamanca, Avd de Alfonso X El Sabio s/n, Facultad de Medicina, Universidad de Salamanca, 37007 Salamanca, Spain. ${ }^{2}$ Day Psychiatric Hospital of the University Clinic Hospital of Salamanca, Salamanca, Spain.

Received: 13 July 2018 Accepted: 26 December 2018

Published online: 23 January 2019

\section{References}

1. Instituto Nacional de Estadística (INE). Encuesta sobre Discapacidades, Autonomía Personal y situaciones de Dependencia 2008. Madrid: INE; 2008. Available at: http://www.ine.es/dyngs/INEbase/es/operacion.htm?c= Estadistica_C\&cid=1254736176782\&menu=resultados\&idp=1254735573175.

2. World Health Organization (WHO). Clasificación internacional del funcionamiento de la discapacidad y de la salud: CIF. Madrid: Ministerio de Trabajo y Asuntos Sociales, Instituto de Migraciones y Servicios Sociales; 2001.

3. Barnett PA, Gotlib IH. Psychosocial functioning and depression: distinguishing among antecedents, concomitants, and consequences. Psychol Bull. 1988;104:97-126.

4. Bisconti TL, Bergeman CS. Perceived social control as a mediator of the relationships among social support, psychological wellbeing and perceived health. J Gerontol B Psychol Sci Soc Sci. 2002:57:387-95.

5. Bukov A, Maas I, Lampert T. Social participation in very old age. J Gerontol B Psychol Sci Soc Sci. 2002;57:510-7.

6. Mirón-Canelo JA, Coco Martín B, Alonso-Sardón M, Maldonado MJ, Iglesias De Sena H. Training curriculum design for all. Madrid: CRUE-Fundación ONCE; 2014.

7. Felce D, Perry J. Quality of life: it's definition and measurement. Res Dev Disabil. 1995;16(1):51-74.

8. Ravaud JF, Delcey M, Yelnik A. Construct validity of the functional independence measure (FIM): questioning the unidimensionality of the scale and the "value" of FIM scores. Scand J Rehabil Med. 1999;31:31-41.

9. De la Revilla L, Baylon E, De Dios J. Validación de una escala de apoyo social funcional para su uso en la consulta del médico de familia. Aten Primaria. 1991;9:668.

10. Bellón JA, Delgado A, De Dios J, Lardelli P. Validez y fiabilidad del cuestionario de apoyo social funcional Duke-UNC-11. Aten Primaria. 1996;18:17-31.

11. Alonso J, Prieto L, Antó JM. La versión española del SF-36 Health Survey (Cuestionario de Salud SF-36): un instrumento para la medida de los resultados clínicos. Med Clin (Barc). 1995:104:771-6.

12. Alonso J, Regidor E, Barrio G, Prieto L, Rodríguez C, De La Fuente De Hoz L. Valores poblacionales de referencia de la versión española del cuestionario de la salud SF-36. Med Clin (Barc). 1998;111:410-6.

13. Badía X. Sobre la adaptación transcultural de medidas de la calidad de vida relacionadas con la salud para su uso en España. Med Clin (España). 1995; 105:56-8.

14. López-García E, Banegas JR, Graciani Pérez-Regadera A, Gutiérrez-Fisac JL, Alonso J, Rodríguez-Artalejo F. Valores de referencia de la versión española del Cuestionario de Salud SF-36 en población adulta de más de 60 años. Med Clin (Barc). 2003;120:568-73.

15. Badia X, Alonso J. La medida de la Salud. In: Guías de escalas de medición en español. 4th ed. Bacelona: Tecnología y Ediciones del conocimiento (EDITTEC); 2007.

16. Regidor E, Barrio G, De la Fuente L, Domingo A, Rodríguez C, Alonso J. Association between educational level and health related quality of life in Spanish adults. J Epidemiol Community Health. 1999;53:75-82.

17. Mirón Canelo JA, Alonso Sardón M, Serrano López de las Hazas A, Sáenz González MC. Health-related quality of life among people with intellectual disabilities in Spain. Pan Am J Public Health. 2008;24(5):336-44.

18. Hensel E. Subjective judgements of quality of life: a comparison study between people with intellectual disability and those without disability. J Intellect Disabil Res. 2002;46(2):95-107.

19. Van Asselt-Goverts AE, Embregts PJ, Hendriks AH. Social networks of people with mild intellectual disabilities: characteristics, satisfaction, wishes and quality of life. J Intellect Disabil Res. 2015;59(5):450-61.

20. Vilaseca R, Gràcia M, Beltran FS, Dalmau M, Alomar E, Adam-Alcocer AL, et al. Needs and supports of people with intellectual disability and their 
families in Catalonia. J Appl Res Intellect Disabil. 2015. https://doi.org/10. 1111/jar.12215.

21. Perry A, Isaacs B. Validity of the family quality of life survey-2006. J Appl Res Intellect Disabil. 2015;28(6):584-8. https://doi.org/10.1111/jar.12141 Epub 2015 Apr 27.

22. Herps MA, Buntinx WH, Schalock RL, van Breukelen GJ, Curfs LM. Individual support plans of people with intellectual disabilities in residential services: content analysis of goals and resources in relation to client characteristics. J Intellect Disabil Res. 2016;60(3):254-62. https://doi.org/10.1111/jir.12245 Epub 2015 Nov 13.

23. Foley KR, Girdler S, Bourke J, Jacoby P, Llewellyn G, Einfeld S, et al. Influence of the environment on participation in social roles for young adults with Down syndrome. PLoS One. 2014;9(9):e108413. https://doi.org/10.1371/ journal.pone.0108413.

24. Molina C, Meléndez JC, Navarro E. Bienestar y calidad de vida en ancianos institucionalizados y no institucionalizados. Anales de Psicología. 2008;24: 312-24.

25. Lunsky Y, Benson BA. Association between perceived social support and strain, and positive and negative outcome for adults with mild intellectual disability. J Intellect Disabil Res. 2001;45(2):106-14.

26. Navas Macho P, Verdugo Alonso MA, Arias Martínez B, Gómez Sánchez L. La conducta adaptativa en personas con discapacidad intelectual. Revista Española sobre Discapacidad Intelectual. 2010;41(3):28-48.

27. Mirón Canelo JA, Alonso Sardón M, Serrano López de las Hazas A. Problemas y necesidades de Salud en personas adultas con discapacidad intelectual. Siglo Cero. 2005:36:25-37.

28. Kouimtsidis C, Fodor-Wynne L, Scior K, Hunter R, Baio G, Pezzoni V, et al. Extended brief intervention to address alcohol misuse in people with mild to moderate intellectual disabilities living in the community (EBI-ID): study protocol for a randomised controlled trial. Trials. 2015;16:114. https://doi. org/10.1186/s13063-015-0629-X.

29. Onrust SA, Romijn G, de Beer Y. Family group conferences within the integrated care system for young people with ID: a controlled study of effects and costs. BMC Health Serv Res. 2015;15:392. https://doi.org/10.1186/ S12913-015-1062-2.

30. Rodríguez-Sánchez E, Mora-Simón S, Porras-Santos N, Patino-Alonso MC, Recio-Rodríguez Jl, Becerro-Muñoz C, et al. Effectiveness of an intervention in groups of family caregivers of dependent patients for their application in primary health centers. Study protocol. BMC Public Health. 2010;10:559. https://doi.org/10.1186/1471-2458-10-559.

31. Zabalegui A, Escobar MA, Cabrera E, Gual MP, Fortuny M, Mach G, et al. Analysis of the educational program for self-care in the elderly (PECA) for improving the quality of life of the elderly. Aten Primaria. 2006;37(5):260-5.

32. García Alcaraz F, Delicado Useros V, Alfaro Espín A, López-Torres Hidalgo J. The use of social health care resources and informal care characteristics care of immobilised homecare patients. Aten Primaria. 2015;47(4):195-204. https://doi.org/10.1016/j.aprim.2014.05.008 Epub 2014 Jul 11.

33. Evenhuis $\mathrm{H}$. Medical aspects of ageing in a population with intellectual disability: III. Mobility, internal conditions and cancer. J Intellect Disabil Res. 1997:41:8-18.

34. Janicki MP, Davidson PW, Henderson CM, McCallion P, Taets JD, Force LT, et al. Health characteristics and health services utilization in older adults with intellectual disability living in community residences. J Intellect Disabil Res. 2002:46:287-98.

35. United Nations (UN). Convention on the rights of persons with disabilities. New York: UN; 2006. Available at: http://www.un.org/spanish/disabilities/ default.asp?id=497.

Ready to submit your research? Choose BMC and benefit from:

- fast, convenient online submission

- thorough peer review by experienced researchers in your field

- rapid publication on acceptance

- support for research data, including large and complex data types

- gold Open Access which fosters wider collaboration and increased citations

- maximum visibility for your research: over $100 \mathrm{M}$ website views per year

At BMC, research is always in progress.

Learn more biomedcentral.com/submissions 